\title{
FenOlogia E BIOLOGIA FLORAL DE NEOGLAZIOVIA VARIEGATA (BROMELIACEAE) NA CAATINGA PARAIBANA ${ }^{1}$
}

\author{
Flavio Robson de Lemos Pereira² \& Zelma Glebya Maciel Quirino ${ }^{3,4}$
}

\section{RESUMO}

(Fenologia e biologia floral de Neoglaziovia variegata (Bromeliaceae) na caatinga paraibana) Este trabalho tem como objetivo conhecer o padrão fenológico e a biologia floral de $N$. variegata. Foram realizadas observações em três populações na fazenda Aragão, município de Campina Grande, PB, no período de maio/ de 2004 a abril de 2005. Foram registrados dados de intensidade e duração das fenofases brotamento, floração e frutificação, e a morfologia das flores, sequiência e duração da antese, concentração e volume de néctar. O comportamento dos visitantes foi descrito através de observações diretas no campo. Neoglaziovia variegata possui flores autocompatíveis e a estratégia de floração é do tipo explosiva. O volume de néctar acumulado foi de $5 \mu$ l, com concentração média de açúcares de $39 \%$. O beija-flor Chlorostilbon aureoventris foi considerado o polinizador efetivo desta espécie. A ornitofilia em Bromeliaceae tem sido interpretada como possível mecanismo de evolução paralela entre bromélias e beija-flores. Neoglaziovia variegata caracteriza-se como mais um exemplo desta estreita relação.

Palavras-chave: ornitofilia, polinização, biologia reprodutiva.

\section{Abstract}

(Phenology and floral biology of Neoglaziovia variegata (Bromeliaceae) in the Paraíba State's 'caatinga') This study subject to investigate the phenological patterns and floral biology of $N$. variegate. Observations were accomplished in three populations in Fazenda Aragão, Campina Grande, PB, since May/2004 until April/ 2005. They had been registered data about intensity and duration of phenophases, leaf flushing, flowering and fruiting, and flower morphology, sequence and anthesis duration, concentration and nectar volume. The visitor's behavior was described through direct observations in the field. Neoglaziovia variegata has selfcompatible flowers and the flowering strategy is explosive. The accumulated nectar volume was $5 \mu$, and the concentration is 39\%. Chlorostilbon aureoventris is considered effective pollinator specie. The ornitophilous in Bromeliaceae has been possible interpreted as mechanism of parallel evolution between Bromeliaceae and hummingbirds. Neoglaziovia variegata is characterized as one more example of this narrow relationship.

Key words: ornitophilous, pollination, reproductive biology.

\section{INTRODUÇÃo}

Bromeliaceae constitui-se numa das maiores famílias botânicas do neotrópico, sendo a única integrante da ordem Bromeliales, com 56 gêneros e 3086 espécies classificadas nas subfamílias, Pitcairnioideae, Tillandsioideae e Bromelioideae, baseando-se os autores nas características dos frutos, sementes e hábito de vida (Smith \& Downs 1979; Luther 2006). Nos últimos anos, novas espécies vêm sendo descritas, o que indica um crescente aumento no conhecimento taxonômico para a família, além de vários estudos sobre os processos ecológicos que regulam a dinâmica de suas populações (ver Siqueira-Filho \& Leme 2006).

Nas Américas a família Bromeliaceae exerce um papel de grande função biológica (Benzing 2000), já tendo sido observado a oferta de recursos de forma contínua, garantindo a manutenção de guildas de diferentes grupos biológicos, como beija-flores, abelhas e morcegos (Martinelli 1997; Buzato et al. 2000; Siqueira Filho \& Machado 1998, 2001, 2006; Sazima et al. 2000), em ecossistemas tropicais. A relação entre a família e polinizadores apresenta um notável adaptação entre planta-

\footnotetext{
Artigo recebido em 03/2007. Aceito para publicação em 10/2008.

${ }^{1}$ Monografia de conclusão de curso do primeiro autor.

${ }^{2}$ Universidade Estadual da Paraíba.

${ }^{3}$ Departamento de Engenharia e Meio Ambiente, Universidade Federal da Paraíba, Campus IV Litoral Norte, Cidade Universitária, C.P. 5065, 58051-970, João Pessoa, PB, Brasil.

${ }^{4}$ Autor para correspondência: zelmaglebya@yahoo.com.br
} 
animal (Benzing et al. 2000), em especial com vertebrados (Sazima et al. 1995), em todos os ambientes estudados. Porém, a maioria dos estudos se reporta a ecossistemas úmidos (Siqueira Filho \& Machado 2006) e, informações sobre a biologia floral de algumas espécies importantes para a manutenção da biodiversidade local, como as que ocorrem na caatinga nordestina, ainda são incipientes.

Neoglaziovia variegata Mez, pertence à subfamília Bromelioideae, é conhecida popularmente como caroá e pode ser encontrada comumente nas microrregiões do Cariri Paraibano. Apresenta potencialidades econômicas centradas nas folhas, as quais se constituem de fibras de alta resistência. $\mathrm{O}$ extrativismo do caroá alcançou níveis significativos na década de 40 , antes do advento das fibras sintéticas, ocasionado pela expansão da lavoura sisaleira (Pereira 2003). Atualmente inicia-se um novo ciclo de exploração da espécie, que, embora endêmica da caatinga e com comprovada importância econômica (Sampaio et al. 2005), ainda não foi estudada quanto a sua biologia reprodutiva.

Com o objetivo de estudar a biologia e a fenologia reprodutiva e vegetativa de $N$. variegata, foi realizado este estudo, buscando descrever o mecanismo reprodutivo, e entender a influência da precipitação nas fenofases. E as possíveis relações com os fatores bióticos (polinizadores), a fim de contribuir para futuros planos de preservação e manejos desta espécie, de interesse econômico e presente em um ecossistema ameaçado como a Caatinga. E assim, finalmente, contribuir para a abordagem ecológica desta família, ampliando as informações sobre os padrões fenológico e de polinização, através de mais um estudo de caso.

\section{Material e Métodos}

\section{Área de estudo}

As observações de campo foram realizadas em uma área de Caatinga, localizada na Fazenda Aragão, zona rural do município de Campina

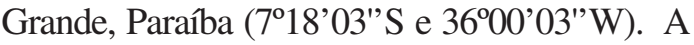
vegetação predominante nesta área é do tipo Savana Estépica Arborizada (Veloso et al. 1991), e os solos mais comuns são os Brunos não cálcicos (pouco espessos e pedregosos) associados à planossolos (Feliciano \& Mélo 2003).

O clima da região é do tipo BSh, segundo a classificação proposta por Köeppen, definido como Semi-árido quente com chuvas de verão (Feliciano \& Mélo 2003), apresentando temperatura média anual em torno de $24^{\circ} \mathrm{C}$, com mínima de $18^{\circ} \mathrm{Ce}$ máxima de $31^{\circ} \mathrm{C}$. A estação chuvosa ocorre nos meses de março a junho, com precipitação média anual de $470 \mathrm{~mm}$, podendo variar entre 300 e 800 $\mathrm{mm}$. A estação seca ocorre entre os meses de julho e fevereiro (Silva et al. 1987).

Os dados climatológicos da região foram obtidos no posto de coleta do Sítio Açude de Dentro, situado a $30 \mathrm{~km}$ do local de estudo, através do Laboratório de Meteorologia Recursos Hídricos e Sensoriamento Remoto da Paraíba (LMRS-PB), órgão vinculado à Secretaria Extraordinária do Meio Ambiente e Recursos Hídricos e Minerais (SEMARH). Os dados de precipitação e temperatura correspondentes ao período em estudo encontram-se na Figura 1a.
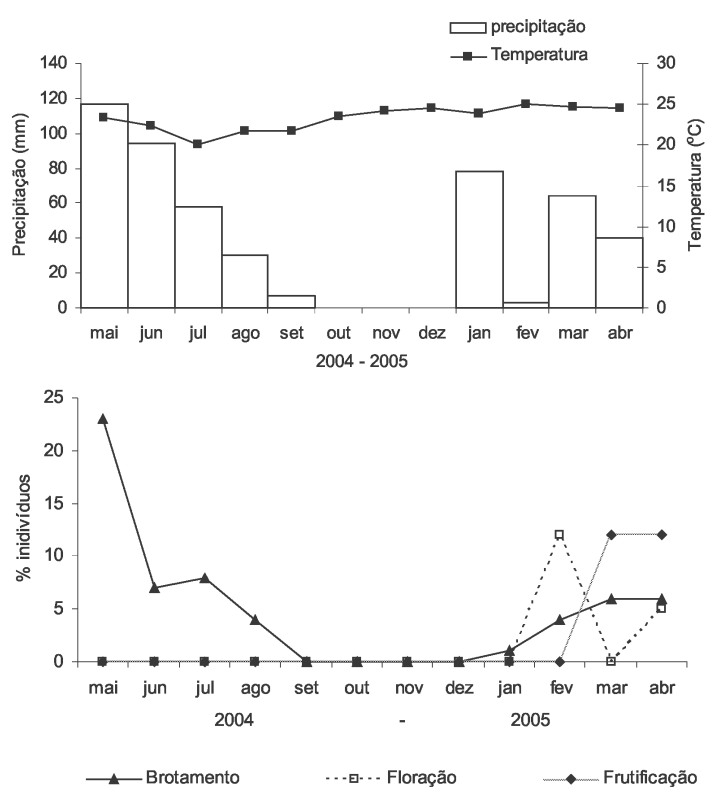

Figura 1 - a. Precipitação e temperatura média mensal no período de maio/2004 a abril/2005, na Fazenda Aragão, Campina Grande-PB. b. Porcentagem de indivíduos de Neoglaziovia variegata nas fenofases de brotamento, floração e frutificação no período de maio/2004 a abril/ 2005, na Fazenda Aragão, Campina Grande, PB. 


\section{Fenologia vegetativa e reprodutiva}

Durante os meses de maio de 2004 a abril de 2005, 30 indivíduos de $N$. variegata, escolhidos aleatoriamente, distribuídos em três agrupamentos distantes entre si $100 \mathrm{~m}$, foram monitorados mensalmente registrando-se os dados sobre presença ou ausência, e duração das fenofases brotamento (emissão de folhas), floração (antese e botão) e frutificação (frutos maduros e imaturos).

Durante a floração foram feitas contagens do número de flores por indivíduo e de flores em antese/dia, determinando-se a estratégia de floração da espécie conforme as classificações de Gentry (1974) e Newstrom et al. (1994).

\section{Morfologia e biologia floral}

No período de floração foram registrados dados sobre as inflorescências e flores, tais como: número, cor, tamanho e disposição das peças florais, emissão de odor, horário, sequência e duração da antese e disponibilidade de pólen. A receptividade do estigma foi testada com peróxido de hidrogênio $\left(\mathrm{H}_{2} \mathrm{O}_{2}\right)($ Galen \& Plowright 1987). No período de frutificação, foi feita a contagem e a descrição morfológica do fruto.

A concentração e volume do néctar foram medidas nas flores $(\mathrm{N}=30)$ em intervalos regulares de duas em duas horas, durante todo o período de antese, com auxílio de microseringas e refratômetro de bolso Atago $\mathrm{n}^{\circ} 1$, respectivamente.

Para verificar a existência de mecanismo de autocompatibilidade, 30 botões em préantese foram ensacados distribuídos em 10 inflorescências, 3 botões/indivíduos em média, durante todo o período de antese. A formação natural dos frutos, controle, também foi observada em 30 inflorescências. Foram também selecionados 30 botões em pré-antese para realização da autopolinização manual e mais 30 para polinização cruzada.

\section{Visitantes florais}

O comportamento dos visitantes às flores foi estudado diretamente no campo, em horários variados do dia, durante toda a fase de pico de floração, perfazendo o total de 240 horas de observação. Durante as sessões de visitas foram registrados aspectos referentes ao período, freqüência (número de visitas), duração, horário e comportamento, bem como o local de contato com o pólen e estigma. De acordo com o comportamento das visitas, foram classificados como polinizadores ou pilhadores.

O material botânico encontra-se depositado no Herbário Lauro Pires Xavier da Universidade Federal da Paraíba (JPB 31204).

\section{Análise estatística dos dados}

Foram realizados teste de correlação de Spearman, através do programa Statistic 6.0, para verificar a existência ou não de correlação entre as fenofases e a precipitação da região no período de estudo.

\section{Resultados \\ Fenologia vegetativa e reprodutiva}

A fenofase de brotamento ocorreu entre os meses de maio e agosto de 2004 e de janeiro a abril de 2005 (Fig. 1b), durante a estação chuvosa. Em maio de 2004 foi observado o maior percentual de plantas na fenofase de brotamento. Foi encontrada uma correlação positiva entre o número de plantas em brotamento e o volume da precipitação do mesmo mês $(\mathrm{r}=0,81 \mathrm{p}<0,05)$ e do mês anterior $(\mathrm{r}=0,73 \mathrm{p}<0,05)$ ao evento. A precipitação, portanto parece desencadear a fenofase, já que no período da estação seca não foram observadas indivíduos em brotamento.

A floração foi observada nos meses de fevereiro e abril de 2005 (Fig. 1b), no período de transição entre o final da estação seca e o início da chuvosa, com o pico de floração no mês de fevereiro. Os resultados obtidos mostram que houve correlação negativa entre a fenofase de floração e a precipitação dos dois meses anteriores a este evento $(r=0,73$ $\mathrm{p}<0,05)$, não havendo correlação significativa para os demais meses. A estratégia de floração apresentada pela espécie é do tipo curta ou 
explosiva e anual, segundo a classificação de Gentry (1974) e Newstrom et al. (1994), respectivamente.

A frutificação ocorreu logo em seguida à floração, nos meses de março-abril de 2005 (Fig. 1b), na estação chuvosa, no entanto, esta fenofase não apresentou correlação significativa com precipitação pluviométrica.

\section{Morfologia e biologia floral}

Neoglaziovia variegata possui inflorescência racemosa do tipo cacho, com escapo floral de coloração avermelhada medindo cerca de $50 \mathrm{~cm}(\mathrm{~N}=10)$ de altura, a qual comporta flores pequenas $(18,4 \mathrm{~mm})$, inodoras, actinomorfas, pediceladas e dispostas de maneira alterna. As medidas das estruturas florais encontram-se na Tabela 1 . O cálice apresenta coloração avermelhada, e a corola lilás, tubulosa.

Cada escapo emitido apresenta de 41-89 ( $X=64, N=30)$ botões, com 3-10 ( $X=5, N=30)$ flores no primeiro dia de antese, sendo que estas permanecem ainda por um período de até 15 dias no escapo, embora murchas. Na infrutescência

Tabela 1 - Média do número de botões por inflorescência, de flores e peças florais, viabilidade polínica e razão pólen/óvulo de Neoglaziovia variegata. $(\mathrm{N}=30)$. $\mathrm{X}=$ média; (máximo-mínimo).

\begin{tabular}{lc}
\hline Caracteres florais & \multicolumn{1}{c}{$(\mathbf{m m})$} \\
\hline Botões/Inflorescência (N=30) & $41-89(\mathrm{X}=64)$ \\
Diâmetro floral & \\
$\quad$ Inserção das pétalas & $3,3(3,1-3,4)$ \\
$\quad$ Abertura do tubo & $7,2(7,1-7,2)$ \\
Comprimento & \\
$\quad$ Floral & $18,4(17,5-18,9)$ \\
Sépala & $10,0(9,8-10,2)$ \\
$\quad$ Pétala & $13,3(13,0-13,5)$ \\
Filete & $16,2(15,8-16,5)$ \\
$\quad$ Estilete & $15,2(14,9-15,3)$ \\
\hline
\end{tabular}

resultante de botões da autopolinização natural, foram observados de 30-74 ( $\mathrm{X}=54, \mathrm{~N}=30)$ frutos em início de desenvolvimento, dos quais apenas de 2 a 15 irão se desenvolver até o final do processo. Os frutos são do tipo baga, com ca. 1,2 × 1,0 cm. O amadurecimento dos frutos ocorre aproximadamente cinco meses após a fecundação. Não houve formação de frutos por polinização manual (autopolinização e cruzada). Na formação natural de frutos, ou seja, controle, foi formado 2-10 frutos por escapo.

As flores de $N$. variegata abrem-se seqüencialmente da base para o ápice da inflorescência, com a antese durando apenas um dia. A antese inicia-se no horário noturno às 1 h40 min, com o afastamento das pétalas, as quais se distorcem formando um pequeno orifício. Neste momento o estigma já se encontra receptivo. A flor encontra-se totalmente aberta às $3 \mathrm{~h} 30 \mathrm{~min}$, com estigma receptivo, recoberto por uma camada úmida e viscosa, e com os grãos de pólen ainda não disponibilizados. Somente às $4 \mathrm{~h} 30 \mathrm{~min}$ as anteras encontram-se deiscentes. $\mathrm{Na}$ antese da flor, o estigma localiza-se próximo aos estames, na porção central do tubo da corola.

A fase final de antese inicia-se por volta das $21 \mathrm{~h} 30$ min quando as flores começam a fechar, contorcendo as pétalas semelhantes à fase de botão. Às $23 \mathrm{~h} 30 \mathrm{~min}$ as flores já se encontram totalmente fechadas, caracterizando o fim da antese. As flores murchas permanecem em média, sete dias no escapo floral.

O néctar é produzido e armazenado na base do tubo da corola em pequenas quantidades, com um volume médio acumulado na flor de $5 \mathrm{ml}$, nas primeiras horas da manhã (entre 6:00h até 8:30h), apresentando uma concentração média de açúcares de 39\%. Após o final da manhã o volume do néctar disponibilizado não foi suficiente para ser calculado.

\section{Visitantes florais}

As flores de $N$. variegata receberam visitas do beija-flor Chlorostilbon aureoventris, da abelha Trigona spinipes e 
da borboleta Junonia evarete, no entanto, apenas $C$. aureoventris foi considerado o polinizador efetivo desta espécie, enquanto os demais visitantes foram considerados pilhadores de pólen e néctar, respectivamente. Esta classificação esta relacionada com o contato observado entre o corpo do visitante e os órgãos reprodutores, no caso dos visitantes foi inexistente, devido à morfologia floral da espécie.

As visitas dos beija-flores iniciaram às 6h15 min estendendo-se até as 16 horas, sendo mais freqüentes no período da manhã, com intervalos de 15 a 20 minutos entre as visitas, totalizando uma média de 18 visitas por inflorescência. No turno da tarde, além de menos freqüentes, os intervalos eram também maiores, variando entre 35 e 45 minutos, totalizando em média 10 visitas por inflorescência.

Durante as visitas, $C$. aureoventris insere o bico duas ou três vezes nas flores, coletando néctar, neste momento também contacta as anteras e/ou o estigma, ficando o pólen aderido à região mediana do bico, permanecendo de 6 a 10 segundos em cada flor, momento em que é realizada a polinização (Fig. 2). A seguir, o animal deslocava-se para outras inflorescências ou para galhos próximos, sem se afastar da planta, reiniciando posteriormente novas visitas, apresentando um comportamento descrito como 'territorialista' (sensu Feinsinger \& Colwell 1978).

Trigona spinipes visitou as flores solitariamente ou em grupos de dois ou três indivíduos, permanecia na flor por longos períodos, sempre pilhando o néctar e coletando pólen, além de eventualmente recortar parte das flores, danificando-as com a dilaceração das anteras e/ou o estigma e filete, inviabilizando o processo de polinização.

Junonia evarete, durante as visitas, insere a longa espirotromba até a base do tubo da corola para coletar néctar, e não contacta as estruturas sexuais. Suas visitas ocorreram ao longo do dia, sendo mais intensas no período entre 10:00h- 15:00h.

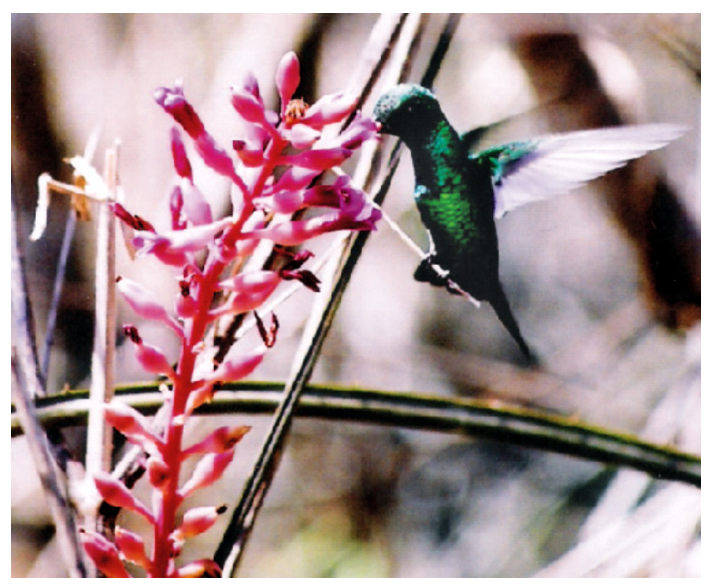

Figura 2 - Visita de Chlorostilbon aureoventris às flores de Neoglaziovia variegata, na Fazenda Aragão, Campina Grande, PB.

\section{Discussão}

Em N. variegata a ocorrência concentrada ao período chuvoso do brotamento indica uma sazonalidade da fenofase, ocorrendo no período mais favorável. Segundo Van Schaik et al. (1993), a emissão sazonal de folhas nas espécies vegetais deve ocorrer em períodos onde as variáveis abióticas sejam capazes de otimizar o início desta fenofase, contrapondo-se às estações desfavoráveis, como em períodos secos, onde a escassez de água pode comprometer o crescimento vegetativo. Estudos abordando o brotamento em espécies de Bromeliaceae geralmente estão relacionados apenas à propagação vegetativa (Benzing 2000), os demais estudos (ver Siqueira-Filho \& Leme 2006) abordam somente as fenofases reprodutivas das espécies, o que acaba impossibilitando comparações entre estes resultados e os obtidos neste estudo.

O período de floração de $N$. variegata influenciado positivamente pela precipitação, já foi relatado para outras duas espécies de bromeliáceas Araeococcus micranthus Brongn e Aechmea beeriana Smith \& Spencer (Nara \& Webber 2002). Embora os autores não tenham feito correlações estatísticas entre este evento fenológico e as variáveis climáticas, os mesmos indicaram a importância do 
estresse hídrico como fator promotor da fenofase de floração. No caso de $N$. variegata, a floração ocorre sempre após o período seco, confirmada por outras observações realizadas por estes autores. O que justificaria também a correlação negativa encontrada. Recentemente, Siqueira-Filho \& Machado (2004) estudando a fenologia da floração de Araeococcus chlorocarpus (Wawra) Leme \& J.A.Siqueira e Lymania smithii Read, observou a ausência de correlação entre a precipitação pluviométrica e o total de plantas floridas. A floração destas espécies ocorreu como um evento sincronizado, também em plena estação seca. Analisando os casos supracitados, parece que a ausência de precipitação pode ser considerada como fator desencadeador da fenofase reprodutiva. Isso é facilmente observado quando analisamos populações em localidades onde a precipitação é ausente no mês de janeiro. Após o início das primeiras chuvas, não ocorre floração para algumas espécies, as quais florescem após a estação seca, como no caso de $N$. variegata. Para outras espécies, este fator atua de forma direta, relacionado possivelmente à intensidade da floração. Porém, outros estudos envolvendo fatores abióticos como precipitação e temperatura, não apenas de forma descritiva, necessitam ser realizados.

A floração do tipo curta ou explosiva e anual observada em $N$. variegata, caracterizase pela abertura anual de um elevado número de flores por planta, em um curto período, sendo semelhante ao observado em outras espécies de Bromeliaceae, tais como Billbergia e Pitcairnia (Siqueira-Filho \& Machado 2004; Nara 1998; Nara \& Webber 2002).

Em $N$. variegata a fenofase de frutificação parece não sofrer influência direta da precipitação, já que esta fenofase ocorre mesmo quando o período chuvoso inexiste. $\mathrm{O}$ processo de amadurecimento dos frutos, uma vez desencadeado, estará submetido a fatores internos e não mais a fatores externos, o que talvez explique a sobreposição das fenofases de floração e frutificação comumente observada para a família Bromeliaceae (Siqueira \&
Machado 1998; Siqueira \& Machado 2001; Nara \& Webber 2002).

A morfologia das flores, assim como a disposição das mesmas no escapo floral, segue o padrão observado paras outras espécies de Bromeliaceae, sugerido como sendo uma tendência evolutiva para plantas ornitófilas (Benzing et al. 2000).

Em $N$. variegata, embora a antese tenha tido início no período noturno, a fase funcional das flores, ou seja, das estruturas reprodutivas produzindo néctar, ocorreu durante o dia. Portanto, considera-se esta espécie como tendo antese diurna. Siqueira-Filho \& Machado (2004) afirmam ser padrão na subfamília Bromelioideae, a antese diurna, com duração de apenas um dia, como no caso da espécie aqui estudada. No entanto, são conhecidos poucos casos de floração noturna, como em Canistrum pickelii (A. Lima \& L. B. Sm.) Leme \& J. A. Siqueira (Siqueira-Filho \& Leme 2002) e Aechmea kleinii Reitz.

Semelhante ao observado em Araeococcus parviflorus (Siqueira-Filho \& Machado 2004), nas flores de $N$. variegata o pólen é liberado algumas horas após o estigma se tornar receptivo, caracterizando assim uma breve dicogamia protogínica. Embora ocorra no período quando ainda não se iniciaram as visitas, parece impedir o contato entre anteras e estigma nos primeiros momentos de antese, impedindo inicialmente a autopolinização. A dicogamia é uma característica comum à maioria das espécies de Bromeliaceae (Martinelli 1997).

As concentrações elevadas de néctar encontrada em $N$. variegata são comuns ao padrão observado para flores melitófilas (Baker 1975; Baker \& Baker 1990). Segundo Buzato et al. (2000), este fato é comum na maioria das Bromeliaceae no sudeste brasileiro, parecendo ser uma tendência evolutiva nesta família.

O teste para verificação da ocorrência de autopolinização indicou que as flores de $N$. variegata são autocompatíveis, uma vez que houve formação de frutos, semelhante ao ocorrido na maioria das espécies desta família 
(McWilliams 1974; Martinelli 1997; SiqueiraFilho \& Machado 2004). Para Benzing (1980), tal condição encontra-se associada frequientemente à polinização por vertebrados, fato observado também nesta espécie.

A disposição central dos elementos sexuais da flor no tubo da corola em $N$. variegata facilita a deposição de pólen no bico dos beija-flores, durante a visita, fato semelhante ao observado por Sazima et al. (1995a) e Fischer \& Araújo (1996) em 17 espécies de Bromeliaceae ornitófilas.

Chlorostilbon aureoventris apresentase como o polinizador efetivo de $N$. variegata. Segundo Leal et al. (2006), em um estudo sobre guildas, esta espécie de beija-flor foi a única a visitar indivíduos de $N$. variegata em uma área de caatinga pernambucana. A polinização de espécies de Bromeliaceae por C. aureoventris foi também observada em Hohenbergia ridleyi (Baker) Mez (SiqueiraFilho \& Machado 1998) e Dyckia tuberosa (Vell.) Berr (Vosgueritchian \& Buzato 2006). A frequiência e as relações com outras espécies de bromélias de diferentes ambientes destacam a importância desta espécie de beija-flor para a reprodução sexuada em Bromeliaceae.

O comportamento oportunista e pilhador de espécies de Trigona já são conhecidos (Sazima \& Sazima 1989). Em algumas espécies de Bromeliaceae reconhecidamente ornitófilas, tais como Billbergia morelii Brongn, Pitcairnia sprucei Baker e Cryptanthus dianae Leme (Siqueira-Filho \& Machado 2006) estas abelhas chegam a comprometer até a viabilidade da flor e isto parece estar relacionado com a escassez de recursos ou perturbação antrópica (SiqueiraFilho \& Machado 2004). A espécie de borboleta apresenta- se apenas como pilhadora, semelhante ao observado para outras espécies da família (Martinelli 1997; Varassin \& Sazima 2000; Vosgueritchian \& Buzato 2006)

De acordo com a classificação de Faegri \& Pijl (1979), as flores de $N$. variegata podem ser consideradas ornitófilas uma vez que, apresentam atributos florais relacionados com esta síndrome, tais como, corola tubulosa, perianto de cores vivas, ausência de odor e presença de néctar como principal recurso floral. A predominância da ornitofilia na família Bromeliaceae, de maneira geral, é confirmada em vários estudos com comunidades neotropicais, sendo considerada a família mais importante na guilda de ornitofilia da Floresta Atlântica do Sudeste do Brasil (Buzato et al. 2000) e do Nordeste (Siqueira-Filho \& Machado 2006).

Na família Bromeliaceae, são conhecidas espécies ornitófilas (McWillians 1974; Ruschi 1982; Frisch \& Frisch 1995), melitófilas (Fischer 1996; Siqueira-Filho \& Machado, 1998; Ramirez et al. 2000), quiropterófilas (Vogel 1969; Sazima et al. 1989, 1995b, 1999), esfingófilas (SiqueiraFilho \& Leme 2002) e até espécies polinizadas por roedores (Cocucci \& Sérsic 1998), conferindo uma ampla irradiação adaptativa a esta família (Benzing 1980, 2000; Vogel 1990). No entanto, a ornitofilia predominante nesta família tem sido interpretada como mecanismo de evolução paralela entre bromélias e beijaflores (Siqueira-Filho \& Machado 1998; Varassin \& Sazima 2000).

Neoglaziovia variegata, embora apresente um sistema reprodutivo autocompatível, possui uma relação de dependência com uma única espécie polinizadora (C. aureoventris), para a permuta de genes entre as populações estudadas e possivelmente entre as demais presentes na Caatinga.

\section{Agradecimentos}

A José Roberto Lima (Herbário UFP) pela organização do material testemunho. Aos revisores anônimos pelas sugestões ao manuscrito.

\section{REFERÊNCIAS BIBLIOGRÁFICAS}

Araújo, A. C.; Fischer, E. A. \& Sazima, M. 1994. Floração seqüencial e polinização de três espécies de Vriesea (Bromeliaceae) na região de Juréia, Sudeste do Brasil. Revista Brasileira de Botânica 17: 113-118.

Baker, H. G. 1975. Sugar concentration in nectars from hummingbird flowers: Biotropica 7: 37-41. 
Baker, H. G. \& Baker, I. 1990. The predictive value of nectar chemistry to the recognition of pollinator types. Israel Journal of Botany 39: 157-166.

Benzing, D. T. 1980. The biology of the bromeliads. Mad River Press, California, 305p.

Benzing, D. H. 2000. Bromeliaceae: Profile of an adaptative radiation. Cambridge University Press, Cambridge, 690 p.

Benzing, D. H.; Luther, H. E. \& Bennett, B. 2000. Reproduction and life history. In: Benzing, D. H. (ed). Bromeliaceae: Profile of an adaptative radiation. Cambridge University Press, Cambridge. Pp. 245-328.

Buzato, S.; Sazima, M. \& Sazima, I. 2000. Hummingbird-pollinated floras at three Atlantic forest sites. Biotropica 2: 824-841.

Cocucci, A. \& Sérsic, A. 1998. Evidence of rodent pollination in subtropical South America In: Owens, S. J. \& Rundall, P. J. (eds). Reproductive biology. Royal Botanical Gardens, Kew. Pp. 113-121.

Faegri, K. \& Pijl, V. D. 1979. The principles of pollination ecology. Pergamon Press, Oxford, New York, 244p.

Feliciano, M. L. M. \& Mélo, R. B. 2003. Atlas do estado da Paraíba: Informação para Gestão do Patrimônio Natural. SEPLAN/ IDEME, João Pessoa, 58p.

Feinsinger, P. \& Colwell, R. K. 1978. Community organization among neotropical nectar-feeding birds. American Zoologist 18: 779-775.

Fischer, E.A. 1996. Polinização por beija-flores In Anais do V Congresso Brasileiro de Ornitologia, Campinas, p.85-90

Fischer, E. \& Araujo, A. C. 1996. The bromeliad flora of the Rio Verde estuary (Juréia, São Paulo): a comparison with other neotropical communities. Journal of the Bromeliad Society 3: 19-25.

Frisch, J. D. \& Frisch, C. A. D. 1995. O jardim dos beija-flores. Dalgas-Ecoltec Ecologia técnica, São Paulo, 272p.

Galen, C. \& Plowright, R. C. 1987. Testing the accuracy of using peroxidase activity to indicate stigma receptivy: Canadian Journal of Botany 65: 107-111.

Gentry, A. H. 1974. Flowering phenology and diversity in tropical Bignoniaceae. Biotropica 6(1): 64-68.

Leal, F. C.; Lopes, A. V. \& Machado, I. C. 2006. Polinização por beija-flores em uma área de caatinga no Município de Floresta, Pernambuco, Nordeste do Brasil. Revista Brasileira de Botânica 29(3): 379-389.

Luther, H. E. 2006. An alphabetical list of bromeliad binomials. Bromeliad Society International, Sarasota, 119p.

Machado, I. C. \& Lopes, A. V. 2003. Recursos florais e sistemas de polinização e sexuais em Caatinga In: Leal, I. R.; Tabarelli, M. \& Da Silva, J. M. C. (eds.). Ecologia e conservação da caatinga. Ed. Universitária da Universidade Federal de Pernambuco, Recife. Pp. 515-559.

Martinelli, G. 1997. Biologia reprodutiva de Bromeliaceae na Reserva Ecológica de Macaé de Cima. In: Lima, H. C. \& Guedes-Bruni, R. R. (org.). Serra de Macaé de Cima: diversidade florística e conservação em Mata Atlântica. Instituto de Pesquisas do Jardim Botânico, Rio de Janeiro. Pp. 213-250.

McWilliams, E. L. 1974. Evolutionary ecology. In: Smith, L. B. \& Downs, R. J. (eds). Bromeliaceae (Pitcairnioideae): Flora Neotropica. Monograph 14. Hafner Press, New York. Pp 40-55

Morellato, L. P. C. \& Leitão-Filho, H. F. 1990. Estratégias fenológicas de espécies arbóreas em floresta mesófila na Serra do Japi. Revista Brasileira de Biologia 50: 163-173.

Nara, A. K. 1998. Biologia floral e polinização de quatro espécies de Bromeliaceae em vegetação de baixio na Amazônia Central. Dissertação de Mestrado. Instituto Nacional de Pesquisas da Amazônia, 82p.

Nara, A. K. \& Webber, A. C. 2002. Biologia floral e polinização de Aechmea beeriana (Bromeliaceae) em vegetação de baixo na Amazônia Central. Acta Amazônica 32(4): 571-588. 
Newstrom, L. E.; Frankie, G. W. \& Baker, H. G. 1994. A new classification for plant phenology based on flowering patterns in Lowland Tropical Rain Forest Trees at La Selva, Costa Rica: Biotropica 26(2): 141-159.

Pereira, D. D. 2003. O Caroá Neoglaziovia variegata Mez no Cariri paraibano: ocorrência, antropização e possibilidades de manejo no assentamento Estrela D'Alva. Dissertação de Mestrado. Prodema/ UFPB-UEPB, João Pessoa, 282p.

Ramirez, R; Chi-May, F.; Carnevali, G.; MayPat, F. \& Chuc-Puc, G. 2000. Portraits of Bromeliaceae from the Mexican Yucatán Peninsula - I: Hechtia schottii Baker ex Hemsley. Journal of the Bromeliad Society 50(1): 20-24.

Reitz, R. 1953. Uma Aechmea de flores noturnas. Anais Botânicos do Herbário Barbosa Rodrigues 5: 253-255.

Ruschi, A. A. 1982. Beija-flores do Estado do Espírito Santo. Editora Rios LTDA. 263p.

Sampaio, E. V. S. B.; Pareyn, F. G. C.; Figueirôa, J. M. \& Santos Jr, A. G. 2005. Espécies da flora nordestina de importância econômica potencial. Vol. 700. Associação Plantas do Nordeste, Recife, 331p.

Sazima, I. \& Sazima, M. 1989. Mamangavas e aripuás (Hymenoptera, Apoidea): visitas, interações e consequiências para a polinização do maracujá (Passifloraceae). Revista Brasileira de Entomologia 33: 109-118.

; Buzato, S. \& Sazima, M. 1995. The saw-billed hermit Ramphodon naevius and its flowers in southeastern Brazil. Journal für ornithologie 36:195-206.

; Vogel, S.; Sazima, M. 1989. Bat pollination of Encholirium glaziovii, a terrestrial bromeliad. Plant Systematics and Evolution 168: 167-179.

Sazima, M.; Buzato, S. \& Sazima, I. 1995. Bat pollination of Vriesea in Southeastern Brazil. Bromelia 2: 29-37.

; Buzato, S. \& Sazima, I. 1999. Batpollinated flower assemblages and bat visitors at two Atlantlic Forest sites in Brazil. Annals of Botany 83: 705-712.

; Buzato, S. \& Sazima, S. \& SAZIMA,

I. 2000. Polinização por beija-flores em

Nidularium e gêneros relacionados. In

Leme E.M.C. Nidularium: Bromélias da Mata Atlântica. Sextante Artes, Rio de Janeiro, 188-195.

Silva, M. A. V.; Braga, C. C.; Aguiar, M. J. N.; Nietzche, M. H. \& Silva, B. B. 1987. Atlas climatológico do estado da Paraíba. $2^{\mathrm{a}}$ ed. Universidade Federal da Paraíba, Núcleo de Meteorologia Aplicada, Campina Grande, 132p.

Siqueira-Filho, J. A. \& Leme, E. M. C. 2002. An addition to the genus Canistrum: a new combination for an old species from Pernambuco and a new species from Alagoas, Brazil. Journal of the Bromeliad Society 52: 105-121. 2006. Fragmentos de Mata Atlântica do Nordeste: biodiversidade, conservação e suas bromélias. Andrea Jakobsson Estúdio, Rio de Janeiro, 416p. \& Machado, I. C. 1998. Biologia floral de Hohenbergia ridleyi (Baker) Mez (Bromeliaceae). Bromélia 5: 1-13. 2001. Biologia reprodutiva de Canistrum aurantiacum E. Morren (Bromeliaceae) em remanescente da Floresta Atlântica, Nordeste do Brasil. Acta Botanica Brasilica 15(3): 497-443. 2004. Síndromes de polinização de uma comunidade de Bromeliaceae e biologia floral de Vriesea psittacina (Hoker) Lindley (Bromeliaceae) em Brejos dos Cavalos, Caruaru, Pernambuco. In: Brejos de Altitude em Pernambuco e Paraíba. História natural, ecologia e conservação. Porto, K. P.; Cabral, J. J. P. \& Tabarelli, M. (orgs.). Ministério do Meio Ambiente, Brasília. Pp. 227-284.

2006. Floração e polinização das bromélias da Mata Atlântica nordestina. In: Siqueira-Filho, J. A. \& Leme, M. C. Fragmentos de Mata Atlântica do 
Nordeste - Biodiversidade, Conservação e suas Bromélias. Andrea Jakobsson Estúdio, Rio de Janeiro. Pp. 158-189. \& Tabarelli, M. 2006. Bromeliad species of the Atlantic forest of north-east Brazil: Losses of critical populations of endemic species. Oryx 40(2): 218-224.

Smith, L. B. \& Downs, R. J. 1979. Bromelioideae (Bromeliaceae). Flora Neotropica Monograph 14(3): 1493-2141.

Van Schaik, C. P.; Terborgh, J. W. \& Wright, S. J. 1993. The phenology of forests: Adaptative significance and consequences for primary consumers. Review of Ecology and Systematics 24: 353-337.

Varassin, I. G. \& Sazima, M. 2000. Recursos de Bromeliaceae utilizados por beija-flores e borboletas em Mata Atlântica do sudeste do Brasil. Boletim Museu de Biologia Mello Leitão 11/12: 57-70.

Veloso, P. H.; Rangel-Filho, A. L. R. E.; Lima, J. C. A. 1991. Classificação da vegetação brasileira adaptada a um sistema universal. IBGE, Rio de Janeiro, 92p.

Vogel, S. 1969. Chiropterophilie in der neotropischen Flora. Neue mitteilungen III Flora abseiling 158: 89-323.

Vogel, S. 1990. Radiación adaptativa del síndrome floral en las famílias neotropicales. Boletim de la Academia Nacional de Ciências. Córdoba 59: 5-13.

Vosguertchian, S. B. \& Buzato, S. 2006. Reprodução sexuada de Dyckia tuberosa (Vell.) Berr (Bromeliaceae, Pitcairnioideae) e a interação planta-animal. Revista Brasileira de Botânica 29(3): 433-442. 